\title{
EFFECT OF MENTORSHIP ON THE EARLY ENTREPRENEURIAL JOURNEY OF UNIVERSITY STUDENTS
}

\author{
Loujein Mouammer $^{a}$ and Carlos Bazan ${ }^{b}$ \\ ${ }^{a}$ Faculty of Engineering \& Applied Science, Memorial University, St. John's, NL Canada \\ ${ }^{\mathrm{b}}$ Faculty of Engineering \& Applied Science and Memorial Centre for Entrepreneurship, \\ Memorial University, St. John's, NL Canada \\ carlos.bazan@mun.ca
}

\begin{abstract}
Acknowledging the value of entrepreneurs in today's society, universities are looking into mentorship to improve their support system for students considering entrepreneurship as a viable career path after graduation. This paper reports the main findings of a systematic literature review aimed at understanding the role that mentorship plays during the early entrepreneurial journey of university students. That is, identifying what motivates students to seek mentorship and recognizing the critical elements of successful mentorship programs that develop robust mentor-mentee relationships.

The systematic literature review classified the selected articles into three thematic categories: mentoring in entrepreneurship, gender differences in mentoring, and mentorship programs in business incubation. Findings in the combined categories suggest that a positive mentoring experience depends on the mentor's credibility and connection in the business world and the mentee's perception of similarities between their mentor and themselves.
\end{abstract}

Keywords: mentorship, entrepreneurship, mentor, mentee, protégé, university.

\section{INTRODUCTION}

An entrepreneur is a person who starts and manages their own business by taking on the full responsibility of its outcomes. Whether seeking satisfaction with their innovation or financial autonomy, entrepreneurs are ready to bear all the risks and challenges the unknown future holds. Nonetheless, not all aspiring entrepreneurs are risk-takers, and many are afraid of the adverse outcomes associated with entrepreneurship. One way to increase the support for students to pursue entrepreneurship is by increasing their psychological safety - the sense of being shielded from adverse situations [1] - by boosting their self-esteem and cognitive ability [2]-[4]. The literature recognizes mentorship for its positive impact on individuals and their organizations. Mentoring is the process of knowledge transfer between a more skilled, experienced person (the mentor) and a novice apprentice (the mentee) [5]. Because of the importance and value of entrepreneurs in today's society, universities are looking into mentorship to improve their support system to encourage more students to consider entrepreneurship a viable career path after graduation. In this context, a systematic and repeatable approach to mentorship can add real value to the entrepreneurial ecosystem in and around the university.

This paper reports the main findings of a systematic literature review by the same authors to understand the role that mentorship plays during the early entrepreneurial journey of university students [6]. That is, identifying what motivates students to seek mentorship and recognizing the critical elements of successful mentorship programs that develop robust mentor-mentee relationships. The rise of entrepreneurial activities directly impacts a region's socioeconomic growth. Innovation, job creation, and wealth generation are essential outcomes that attract policymakers towards supporting more entrepreneurial initiatives. The world is witnessing an increase in entrepreneurship training and education offered by higher educational institutions and the impact that these programs have on students' attitudes towards entrepreneurship [7].

Consequently, an increasing number of practical tools to promote and teach entrepreneurship are being developed and adopted, e.g., lean startup methodology [8]. Post-secondary institutions are now aware that a higher chance of producing more entrepreneurs in the future relies on developing entrepreneurial skills that a student can achieve during their university program. According to GEM's 2018/2019 Global Report, recent university graduates fall within the most popular age group of entrepreneurs (24-35) in almost every geographic region [9]. This is consistent with findings by Blanchflower et al. [10], which argue that the willingness to be self-employed is more common among the younger generation and decreases with age. Furthermore, with the heightened employment difficulties and improved satisfaction of self-employment, students are conveying an increased interest in university-offered entrepreneurship programs [11].

The authors conducted a systematic literature review to answer the following two research questions. 1) What 
effects do mentorship programs have on entrepreneurial university students? 2) What mentorship programs do organizations use to support entrepreneurial university students? To answer these questions, the authors searched the SCOPUS electronic database platform (the largest citation database of peer-reviewed literature) from inception until January 2020. Furthermore, they carefully applied a systematic and repeatable approach to identify relevant publications that include the desired information. Their query returned 219 publications that met the search criteria, of which 141 documents appear in scientific or professional journals (articles and reviews), 64 documents are included in conference proceedings, 13 documents are parts of book publications and one undefined. (The authors assumed that journal articles were the only document type validated by peer-review.) With the 141 journal documents, the authors performed a citation analysis to point out the main articles in the field. Citation frequency is a popular metric used to assess published articles according to their value [12]. The authors then arranged the articles to follow the order from most cited to least cited articles. They first read all the abstracts as a quick way to assess the relevance of the articles in answering the research questions. They read the full article when they could not reach a conclusion based on the abstract solely. This screening produced 82 documents that they retrieved for further scrutiny. (Due to space limitations, the complete list of articles is available upon request.) The authors focused their attention on selecting journal articles that referred to the influence of mentorship in the context of entrepreneurship on university students' behaviour. This inclusion criterion resulted in 30 documents that they examined thoroughly. The authors also scrutinized the references of these articles and retrieved five supplementary documents.

\section{RESULTS AND FINDINGS}

While analyzing the journal articles, the authors separated the documents into three different categories depending on the theme of each paper: mentoring role in entrepreneurship, gender differences in mentoring, or mentorship programs in business incubation. From the articles selected, 16 papers fit the category regarding the role that mentoring plays in entrepreneurship, 10 articles address mentorship needs based on gender differences, and nine documents deal with mentorship models in business incubation. A narrative synthesis of the three themes identified in the literature review follows.

\subsection{Mentoring in Entrepreneurship}

Many scholars have studied the purpose and benefits of mentoring in entrepreneurship. Most scholars regard mentoring as a practical means of teaching enterprise [13] and a mechanism to facilitate opportunity recognition by promoting a well-developed schema [14]. While most studies considered the typical one-to-one mentoring format, some scholars have looked into alternative mentoring arrangements such as group mentoring, i.e., one-to-many [15], and e-mentoring [16]. Among others, the results of studies in this category can help understand the mentormentee relationship. Some of these results are as follows. Memon et al. [17] proposed applying a theoretical framework to create a long-lasting relationship that will lead to mentee satisfaction and help them achieve their entrepreneurial goals. The data collected based on their framework can also help create a psychological profile of mentees, which can help a mentor understand their mentee more fully. Ozgen and Baron [14] were able to link the benefits of having a mentor to the schema strength of their mentee. They argue that the higher the person's schema strength, the more confident they will feel, which will increase their self-efficacy. They also suggest that the mechanism that mentors can use to facilitate opportunity recognition is by promoting the formation of a well-developed schema. Memon et al. [18] proposed a conceptual model for mentors. They argued that mentees might need different mentoring support and skills depending on their type, personality traits, decision-making style, and stage of entrepreneurial development, i.e., initiation, cultivation, separation, and redefinition. St-Jean et al. [19] tested the combined effects of the mentee's learning goal orientation and perceived similarity with the mentor and demonstrated the role of these two variables in mentoring relationships. Their findings indicate that the development of entrepreneurial selfefficacy is optimal when mentees present low levels of learning goal orientation and perceive high similarities between their mentor and themselves. Ting et al. [20] explored the mentoring effect and its determinants in the Chinese context by building a conceptual framework and using empirical analysis. They concluded that among the mentor's characteristics, i.e., intention, quality, and skill, their intention has the most significant influence on the mentoring effect, determined by the interaction of the mentor, the mentee, and their interactive relationship.

Results of studies in this category can also help understand the mentor-mentee relationship by considering the format of the relationship. Some of these results are as follows. Gimmon [13] explored innovative ways of bringing an active mentoring environment for entrepreneurs to an academic setting. Students who participated in this program showed a deeper understanding of entrepreneurship, improvement in entrepreneurial traits, and higher self-efficacy than their peers who did not participate in the program. Bisk [21] evaluated mentees' satisfaction with the mentoring relationship and their perception of the effectiveness of their assigned mentors from third-party managed entrepreneurial mentoring programs. His results suggest that the education and age of the mentee can influence whether they benefit from the engagement. They also indicate that mentors need not have experience in the industry of their mentee for the entrepreneur to benefit from the interaction. Kroll [15] evaluated contemporary experiences 
of group mentoring and highlighted the powerful nature of these developmental experiences for individuals and communities. His analysis showed that "group mentoring has resulted in individuals seeing themselves as valuable and valued to others, gaining access to networks, increasing confidence levels, progressing in career, and having a deepened understanding of self." Leppisaari and Tenhunen [16] assessed the applicability of e-mentoring models for staff development of small- and medium-sized enterprises. Their results indicate that e-mentoring can facilitate support from experienced entrepreneurs in practical professional development and that participants prefer peer mentoring online over one-on-one expert e-mentoring. St-Jean et al. [22] studied the role of mentors who are in business as opportunity brokers and enablers among university students with entrepreneurial intentions. Their findings indicate that, contrary to other mentors, mentors who are in business can support opportunity identification and exploitation among university students. They also argue that mentoring is among the few elements that can be controlled for during the creation of formal entrepreneurial support programs. Moore and Wang [23] studied the relationship between mentoring higher-level leadership - such as CEOs - and organizational innovativeness. Their findings confirm that mentoring the top leaders relates positively to their perceived organization's innovativeness and that the mentee's perception of psychological safety within the organization mediates that relationship.

\subsection{Gender Differences in Mentoring}

Studies in this category investigated the gender differences in entrepreneurship as influenced by mentoring (among other factors). While some studies focused on gender differences in specific cultures [24], [25], most studies aimed at understanding the challenges faced by female entrepreneurs and how mentoring and other resources (e.g., entrepreneurship education, funding) can help reduce these constraints [26]-[28]. Some of these findings are as follows. Dabic et al. [26] studied gender differences in entrepreneurial intentions. They explored gender differences in perceptions of entrepreneurship education needs to succeed in an entrepreneurial career from the university students' point of view. Students in their study cited entrepreneurial mentoring and an appropriate tutoring structure as the most needed entrepreneurship educational element at an academic institution. Females rated the need for mentoring higher compared to males. Logan [28] investigated the motivations, goals, challenges, successes, and needs of older women starting new ventures. Her findings suggest that well-trained mentors could make a significant difference to an older cohort of female entrepreneurs, particularly in terms of helping them to grow their businesses. Mattis [29] studied women business owners who left corporate careers to start their own businesses. An interesting finding of her study was that one reason for these women leaving their corporate careers was the "lack of role models and mentors" in their previous organizations. Coleman and Robb [30] investigated the first Rising Tide Training Program cohort regarding changes in participants' motivations, attitudes, and expectations related to angel investing. In particular, they analyzed the program's effect in seeking to address structural weaknesses in a critical component of the entrepreneurial ecosystem, such as women's access to financial capital in the form of equity, mentorship, and contacts. Tynan [31] shared their experience designing and implementing an enterprise development program for female entrepreneurs who already own their businesses and want to grow them further. Their experience revealed that, among other factors, the networking and mentoring aspects of the program were very beneficial to the participants.

The challenges facing female entrepreneurs relate closely to the culture in which they try to start their own businesses. Some of the learnings regarding the help that mentoring and other resources can provide in this case are as follows. Apergis and Pekka-Economou [24] examined personal characteristics and motivation incentives to determine the significant factors that may influence the female entrepreneurial spirit in Greece. They found that an effective mentoring framework is an essential factor for encouraging women to start a new business. Danish and Smith [25] explored the challenges facing female entrepreneurs in Saudi Arabia and found that female entrepreneurship is growing despite significant societal and institutional challenges. Their results suggest that the provision of resources, training, and mentoring and eliminating some of the administrative procedures requiring male representation during the establishment and financing would significantly improve female entrepreneurship. De Villiers Scheepers [32] examined how women's career phase and Ubuntu (collectivist) values relate to their cognitive ambidexterity when pursuing entrepreneurial initiatives in South Africa. Their findings suggest that entrepreneurial women who develop their cognitive ambidexterity and draw on both effectual and causal approaches when initiating entrepreneurial endeavours are more likely to experience successful outcomes. They also suggest that women can develop these mental approaches through awareness, training, and mentoring. Davis [27] studied the needs of women entrepreneurs in terms of service areas and delivery methods in rural and urban areas. Their findings suggest two important service need areas: "how to find mentors and role models" and "legal issues," regardless of the location of the entrepreneur.

Female university students are underrepresented in entrepreneurship education programs and science, technology, engineering, and mathematics (STEM) programs. This lack of representation gets exacerbated in STEM entrepreneurship. Elliot et al. [33] studied gender-sensitive entrepreneurship education and peer mentoring programs for women engineering and computer science students de- 
veloped at a Canadian university to provide classroom instruction, experiential learning, and support to a small group of students. One of the significant findings of their study is that a gender-sensitive mentorship program can develop entrepreneurial identity among women engineers. Elliot et al. [34] reported the preliminary findings on the novel Women's Start-up Network program at the University of Ottawa. The program's objective was to develop an entrepreneurial mindset and competencies in female engineering and computer science students through facilitated peer mentorship training. Overall, the program was deemed successful in increasing entrepreneurial intent, entrepreneurial self-efficacy, and overall confidence and providing social support and networking for women in the Faculty of Engineering.

\subsection{Mentoring in Business Incubation}

Entrepreneurship centres, business incubators, and accelerators are essential components of today's entrepreneurial ecosystems [35]. Scholars have been studying the effect of mentoring programs (among others) in these organizations designed to influence entrepreneurs' ability to access, interpret, and process the external information needed to survive and grow [36], [37]. The study of mentoring in business incubation is intimately related to the ecosystem in which they operate-such as in an entrepreneurial university [38], [39]. Some of the results in this category are as follows. Bell and Bell [35] investigated the benefits to students and external stakeholders and the associated impact on faculty from an extracurricular entrepreneurial learning approach focused on networking, mentoring, and venture creation adopted as a substitute for activities in an entrepreneurship centre. Students in the study reported that the mentors helped them understand the business startup process and that mentoring added to their confidence in interacting with professionals and starting a business by demystifying the process and receiving constructive feedback. Cohen, Bingham, et al. [36] investigated the influence of business accelerators on the success of new ventures. Their findings provide evidence that bounded rationality challenges new ventures differently from established firms. They also identified consultations with mentors and customers as particular organizational designs that accelerators use to help address these challenges. Cohen, Fehder et al. [40] related the key variations in the antecedents, organizational design, and operation of programs in accelerators - such as mentoring - to theories of firm-level entrepreneurial performance. They could probe the connections between design and performance in an integrative way and expand our understanding of startup intermediaries, not just business accelerators.

Hernández and González [38] argued that startups are inevitably part of an ecosystem consisting of resources and assets - including mentors - that help ventures in their journey. They offered an overview of the technology-based ecosystem status in Lima, Peru and highlighted, among others, the importance of mentoring both from local mentors and mentors in other ecosystems. Hernández and González [39] analysed the interactions that occur in the LinkedIn ${ }^{\circledR}$ social network platform to understand the interorganizational networks established on the entrepreneurial ecosystem in Lima, Peru. They observed that startups and mentors (community of entrepreneurs) together constitute the largest percentage of entities in the network. Huster et al. [41] conducted a program evaluation of the first nine years of the Global Social Entrepreneurship Competition at the University of Washington to assess the outcome of participation. Their findings show that finalist teams considered networking and mentoring as key benefits of participation. Lalkaka [37] studied the distinguishing characteristics of business incubators in selected developing countries. His findings identify the determinants of success in the Olympiad of Venture Creation: a public policy that stimulates entrepreneurial businesses and provides the business infrastructure; private sector partnerships for mentoring and marketing; knowledge base of learning and research; national and global professional networking; and community involvement to promote entrepreneurism and cultural change.

\section{DISCUSSION}

While many factors such as gender, work experience, and level of education can influence a student's decision about considering an entrepreneurial path, mentoring offered by entrepreneurship centres is among the few elements that a university can control [22]. The three general functions that mentoring programs aim to provide are professional support, psychosocial support, and role modelling [23]. In the entrepreneurial world, mentoring translates to an opportunity for the mentee to form a professional and supportive network, a space to validate business ideas with lower risk, and a tool to enhance their confidence and decision-making process [14], [42]. Success in entrepreneurship mentoring programs can be attributed to more than one factor, of which diversity of mentors and their connections in the business world [22], [35], mentee's perception of similarities to a mentor [17], and mentor's credibility play significant roles [42].

This paper aims to provide suggestions and best practices on improving the mentoring experience for students who wish to pursue an entrepreneurial path. For this, the research focused on the common challenges faced by the current mentoring programs. Many studies have linked the success of business ventures to networking and mentoring programs [43]. Nascent entrepreneurs such as undergraduate students with limited network and work experience, in particular, could benefit the most from mentoring programs [14], [44]. While mentoring relationships can be offered in several forms, the most popular at universities is in a dyad form, i.e., one-to-one. Even though engaging with professional mentors on a one-to-one basis can help increase a 
student's confidence with interacting with professionals [35], this form of interaction can also introduce a hierarchy [15], [45] in which mentors take a leading role and mentees follow. While this type of one-way exchange of knowledge is helpful in many cases, it very much depends on the mentor's credibility and ability to lead the mentee in the right direction. Unlike a dyad mentoring approach, a lateral relationship often found in peer-group mentoring is a twoway exchange of knowledge. While both mentoring relationships form strong ties, peer mentoring groups experience higher motivation for mentoring as they are united by a common purpose, to learn and support each other [45]. Hierarchy dissolves as each group member shares a valuable and unique experience [15]. Another benefit of this less traditional peer mentoring approach is that it provides a practical entrepreneurial experience, which improves a student's self-efficacy and entrepreneurial abilities [13].

A mentoring program can form strong and lasting mentoring relationships by understanding the four different stages a successful mentoring relationship passes through, as shown in Table 1.

Table 1: Stages of Mentoring [18].

\begin{tabular}{|ll|}
\hline \multicolumn{1}{|c|}{ Initiation } \\
\hline - & Engagement phase \\
\hline & Establishing identity of dyad as entity \\
\hline - & Active phase \\
- & Confirmativation \\
- & Inforr relational boundaries \\
\hline & \multicolumn{1}{c|}{ Separation } \\
\hline - & Ending phase \\
\hline & \multicolumn{1}{c|}{ Physical and emotional separation } \\
\hline - & Friendship phase \\
\hline & Supportive colleagues \\
\hline
\end{tabular}

St-Jean et al. [19] found that the higher the perceived similarity (age, gender, background) between the mentee and the mentor, the more significant the role model's impact on the mentee's entrepreneurial self-efficacy. Memon et al. [17] also found that perceived similarity between the mentor and mentee could affect the willingness to self-disclose and can play an essential role in forming a long-lasting relationship. Therefore, in the initiation stage, both parties - mentor and mentee-should review their profiles and assess the suitability of the match [18]. Promoting effective communication is the key to forming a meaningful cultivation stage. While the mentoring program is one of the few factors that an entrepreneurship centre could control, interest and motivation might vary highly from one mentor to another. A mentee could experience an unhealthy mentoring relationship since not all mentors are equally invested [19]. Ting et al. [20] argued that a mentor's intention has a significantly higher effect on the mentoring program's success than the mentor's quality and skills. To guarantee a successful mentoring program, entrepreneurship centres should focus on recruiting from a group of high-quality mentors and continuously motivate mentors by offering financial and symbolic awards [20]. The separation stage is the termination of the relationship as the program reaches its end. However, students are encouraged to take their new networking relationship outside of the program [35], which can help redefine the mentor and mentee relationship and form a more extended friendship [18].

The first step in improving an entrepreneurship mentoring program is to improve participation. While the regular in-person mentoring program offers a unique learning experience, it is less accessible and unintentionally limits diversity. With the latest technology advancements, ementoring complementary to face-to-face mentoring can be an effective tool to promote equal access to mentoring opportunities and avoid limitations of physical space and time [16]. Leppisaari and Tenhunen [16] showed that women demonstrated a higher interest in an online mentoring program. It is important to note that security and privacy challenges with an online tool remain a concern. Therefore, it is beneficial to weigh the advantages and disadvantages based on program location, access to a good pool of mentors, and participants' preference.

Studies also indicate that different genders approach entrepreneurship and self-employment differently. Most research shows that female entrepreneurs tend to have lower risk-tolerance and self-efficacy than their fellow male entrepreneurs. This plays an essential factor in their entrepreneurial intention [26]. However, businesses started by women will diversify and expand opportunities in the economy because of their interest in solving different problems. Even though most communities see an increase in the number of females in entrepreneurship, the percentage is still typically lower than male entrepreneurs. Findings from the literature suggest that increasing access to female mentors in entrepreneurship mentoring programs is essential to promote entrepreneurship among female students and will help in boosting their self-confidence in starting their own business. Gender matching in mentoring programs is more important to women. Research shows that more effective and active communication occurs in a female mentor-female mentee relationship [17], [19]. Structural barriers such as time and duration of mentoring sessions could limit female student participation, especially with women pursuing careers in STEM. Packard [46] posed a challenge to the traditional mentoring definition of a dyad relationship between two people to expand it to include e-mentoring and an online resource library. Mentoring, especially with the technology available today, cannot be limited to forming 
relationships. Programs should try to find other ways to derive solutions, whether through articles, listserv, bulletin boards, counselling, etc.

\section{CONCLUSION}

The purpose of this paper is to understand the mechanisms behind mentorship, the positive and negative impact it has on university students' pursuit of entrepreneurship, and provide suggestions and recommendations for university mentorship programs. The systematic literature review helps surface the evidence gathered on the role of mentorship on university students' entrepreneurial journey. Mentoring provides a wide array of professional, psychological, and psychosocial support [18], [23]. Connecting with a mentor can also mean connecting with a real-life role model who can help give university students a more practical and authentic entrepreneurial experience [13]. When implementing mentorship in entrepreneurship programs, students will gain a broader perspective, which can help them cope with the scary unknowns associated with starting a new business. In their study, Ozgen and Baron [14] identified that opportunity recognition and schema strength were two positive mentorship outcomes.

Furthermore, St-Jean et al. [22] showed that mentors in the business sector could bolster students' opportunity recognition compared to other mentors. Mentorship is not considered a standard process and can occur in several forms that allow mentors to wear many hats [17]. Memon et al. [18] recognized different types of entrepreneurs. They proposed that mentoring support should vary based on both the personality of the entrepreneurs and where they are in their entrepreneurial journey. Gender is another factor that plays a considerable role in students' entrepreneurial intention, and it is essential to reflect on how mentorship can affect the gender gap in entrepreneurship. In a study performed by Dabic et al. [26], female students ranked entrepreneurial mentoring as a top activity necessary in the entrepreneurial centre of an academic institution.

\section{Acknowledgements}

The authors acknowledge the support from the Atlantic Canada Opportunity Agency (ACOA), Newfoundland and Labrador's Department of Tourism, Culture, Industry and Innovation (TCII), and the Memorial Centre for Entrepreneurship (MCE). The corresponding author also acknowledges the additional support provided by the Office of the Vice-President (Research), the Office of the Dean of Engineering \& Applied Science, and the Office of the Dean of Business Administration at Memorial University.

\section{References}

[1] W. A. Kahn, "Psychological conditions of personal engagement and disengagement at work," Acad. Manag.
J., vol. 33, no. 4, pp. 692-724, 1990.

[2] J. M. Haynie, D. Shepherd, E. Mosakowski, and P. C. Earley, "A situated metacognitive model of the entrepreneurial mindset," J. Bus. Ventur., vol. 25, no. 2, pp. 217-229, 2010.

[3] R. A. Baron and M. D. Ensley, "Opportunity recognition as the detection of meaningful patterns: Evidence from comparisons of novice and experienced entrepreneurs," Manage. Sci., vol. 52, no. 9, pp. 1331-1344, 2006.

[4] N. Krueger and P. Dickson, "How Believing in Ourselves Increases Risk Taking: Perceived SelfEfficacy and Opportunity Recognition," Decis. Sci., vol. 25 , no. 3, pp. 385-400, 1994.

[5] B. Bozeman and M. K. Feeney, "Toward a useful theory of mentoring: A conceptual analysis and critique," Adm. Soc., vol. 39, no. 6, pp. 719-739, 2007.

[6] L. Mouammer and C. Bazan, "Effect of Mentorship on the Early Entrepreneurial Journey of University Students: A Systematic Literature Review," St John's, NL, 2021.

[7] C. Jones, H. Matlay, and A. Maritz, "Enterprise education: For all, or just some?," Educ. Train., vol. 54, no. 8, pp. 813-824, 2012.

[8] S. Blank, "Why the Lean Start Up Changes Everything," Harv. Bus. Rev., vol. 91, no. 5, p. 64, 2013.

[9] N. Bosma and D. Kelley, Global Entrepreneurship Monitor Report: 2018/2019. 2019.

[10] D. G. G. Blanchflower, A. Oswald, and A. Stutzer, "Latent entrepreneurship across nations," Eur. Econ. Rev., vol. 45, no. 4-6, pp. 680-691, 2001.

[11] D. Schwartz and A. Malach-Pines, "Entrepreneurship Education for Students: How Should Universities Prepare for the Challenge of Teaching Entrepreneurship?," Ind. High. Educ., vol. 23, no. 3, pp. 221-231, 2009.

[12] J. (Melanie) Xi, S. Kraus, M. Filser, and F. W. Kellermanns, "Mapping the field of family business research: past trends and future directions," Int. Entrep. Manag. J., vol. 11, no. 1, pp. 113-132, 2013.

[13] E. Gimmon, "Mentoring as a practical training in higher education of entrepreneurship," Educ. Train., vol. 56, pp. 814-825, 2014.

[14] E. Ozgen and R. A. Baron, "Social sources of information in opportunity recognition: Effects of mentors, industry networks, and professional forums," $J$. Bus. Ventur., vol. 22, no. 2, pp. 174-192, 2007.

[15] J. Kroll, "What Is Meant By The Term Group Mentoring?," Mentor. Tutoring Partnersh. Learn., vol. 24, no. 1, pp. 44-58, 2016.

[16] I. Leppisaari and M. L. Tenhunen, "Searching for ementoring practices for SME staff development," Serv. Bus., vol. 3, no. 2, pp. 189-207, 2009.

[17] J. Memon, M. Z. A. Rozan, K. Ismail, M. Uddin, A. Balaid, and D. Daud, "A theoretical framework for mentor-protégé matchmaking: The role of mentoring in entrepreneurship," Int. J. Green Econ., vol. 8, no. 3-4, pp. 252-572, 2014.

[18] J. Memon, M. Z. A. Rozan, K. Ismail, M. Uddin, and D. K. Daud, "Mentoring an entrepreneur: Guide for a mentor," SAGE Open, vol. 5, no. 1, 2015.

[19] E. St-Jean, M. Radu-Lefebvre, and C. Mathieu, "Can less be more? Mentoring functions, learning goal 
orientation, and novice entrepreneurs' self-efficacy," Int. J. Entrep. Behav. Res., vol. 24, no. 1, pp. 2-21, 2018.

[20] S. X. Ting, L. Feng, and W. Qin, "The effect of entrepreneur mentoring and its determinants in the Chinese context," Manag. Decis., vol. 55, no. 7, pp. 1410-1425, 2017.

[21] L. Bisk, "Formal entrepreneurial mentoring: The efficacy of third party managed programs," Career Dev. Int., vol. 7, no. 5, pp. 262-270, 2002.

[22] É. St-Jean, M. Tremblay, F. Janssen, J. Baronet, C. Loué, and A. Nafa, "May business mentors act as opportunity brokers and enablers among university students?," Int. Entrep. Manag. J., vol. 13, no. 1, pp. 97-111, 2017.

[23] J. H. Moore and Z. Wang, "Mentoring top leadership promotes organizational innovativeness through psychological safety and is moderated by cognitive adaptability," Front. Psychol., vol. 8, no. MAR, pp. 110, 2017.

[24] N. Apergis and V. Pekka-Economou, "Incentives and Female Entrepreneurial Activity: Evidence from Panel Firm Level Data," Int. Adv. Econ. Res., vol. 16, no. 4, pp. 371-387, 2010.

[25] A. Y. Danish and H. L. Smith, "Female entrepreneurship in Saudi Arabia: Opportunities and challenges," Int. J. Gend. Entrep., vol. 4, no. 3, pp. 216-235, 2012.

[26] M. Dabic, T. Daim, E. Bayraktaroglu, I. Novak, and M. Basic, "Exploring gender differences in attitudes of university students towards entrepreneurship: An international survey," Int. J. Gend. Entrep., 2012.

[27] A. Davis, "Rural and urban women entrepreneurs: A comparison of service needs and delivery methods priorities," Int. J. Bus. Sci. Appl. Manag., vol. 6, no. 2, pp. 1-16, 2011.

[28] J. Logan, "An exploration of the challenges facing women starting business at fifty," Int. J. Gend. Entrep., vol. 6 , no. 1, pp. 83-96, 2014.

[29] M. C. Mattis, "Women entrepreneurs: out from under the glass ceiling," Women Manag. Rev., vol. 19, no. 3, pp. 154-163, 2004.

[30] S. Coleman and A. Robb, "Executive forum:linking women's growth-oriented entrepreneurship policy and practice: results from the Rising Tide Angel Training Program," Ventur. Cap., vol. 20, no. 2, pp. 211-231, 2018.

[31] M. Tynan, D. Thomas, B. O'Gorman, N. Fuller-Love, and M. Durand, "Training female entrepreneurs: Lessons from the FEIW project," Int. J. Gend. Entrep., vol. 1, no. 3, pp. 253-260, 2009.

[32] M. J. De Villiers Scheepers, C. Boshoff, and M. Oostenbrink, "Entrepreneurial women's cognitive ambidexterity: Career and cultural influences," South African J. Bus. Manag., vol. 48, no. 4, pp. 21-33, 2018.

[33] C. Elliott, C. Mavriplis, and H. Anis, "An entrepreneurship education and peer mentoring program for women in STEM: mentors' experiences and perceptions of entrepreneurial self-efficacy and intent," Int. Entrep. Manag. J., vol. 16, no. 1, pp. 43-67, Mar.
2020.

[34] C. Elliott, H. Anis, and C. Mavriplis, "Peer Mentoring in Engineering Entrepreneurship: A Learning Environment for Women Students," in Proceedings of the 2016 Canadian Engineering Education Association (CEEA16) Conference, 2016, pp. 1-8.

[35] R. Bell and H. Bell, "Replicating the networking, mentoring and venture creation benefits of entrepreneurship centres on a shoestring: A studentcentred approach to entrepreneurship education and venture creation," Ind. High. Educ., vol. 30, no. 5, pp. 334-343, 2016.

[36] S. Cohen, C. Bingham, and B. Hallen, "The Role of Accelerator Designs in Mitigating Bounded Rationality in New Ventures," Adm. Sci. Q., vol. 64, no. 4, pp. 810 854, 2019.

[37] R. Lalkaka, "Business incubators in developing countries: Characteristics and performance," Int. J. Entrep. Innov. Manag., vol. 3, no. 1/2, pp. 31-53, 2003.

[38] C. Hernández and D. González, "Study of the Start-Up Ecosystem in Lima, Peru: Collective Case Study," Lat. Am. Bus. Rev., vol. 17, no. 2, pp. 115-137, 2016.

[39] C. Hernández and D. González, "Study of the start-up ecosystem in Lima, Peru: Analysis of interorganizational networks," J. Technol. Manag. Innov., vol. 12, no. 1, pp. 71-83, 2017.

[40] S. Cohen, D. Fehder, Y. Hochberg, and F. Murray, "The design of startup accelerators," Res. Policy, vol. 48, no. 7, pp. 1781-1797, 2019.

[41] K. Huster, C. Petrillo, G. O’Malley, D. Glassman, J. Rush, and J. Wasserheit, "Global Social Entrepreneurship Competitions: Incubators for Innovations in Global Health?," J. Manag. Educ., 2017.

[42] D. McKevitt and D. Marshall, "The legitimacy of entrepreneurial mentoring," Int. J. Entrep. Behav. Res., vol. 21 , no. 2 , pp. 263-280, 2015.

[43] B. R. Ragins, J. L. Cotton, and J. S. Miller, "Marginal mentoring: The effects of type of mentor, quality of relationship, and program design on work and career attitudes," Acad. Manag. J., vol. 43, no. 5, pp. $1177-$ 1194, 2000.

[44] R. Sullivan, "Entrepreneurial learning and mentoring," Int. J. Entrep. Behav. Res., vol. 6, no. 3, pp. 160-175, 2000.

[45] S. Sarkar, O. Osiyevskyy, and L. Hayes, "Talking Your Way into Entrepreneurial Support: An Analysis of Satisfaction Drivers in Entrepreneur Mutual Aid Groups,” J. Small Bus. Manag., vol. 57, no. 2, pp. 275 297, 2019.

[46] B. W. L. Packard, "Web-based mentoring: Challenging traditional models to increase women's access," Mentor. Tutoring Partnersh. Learn., vol. 11, no. 1, pp. 53-65, 2003. 